\title{
Distal Renal Tubular Acidosis
}

\author{
Hassan Mumtaz ${ }^{1 *}$, Ayesha Tariq ${ }^{2}$, Sara Shohab ${ }^{2}$, Kainat Mustafa ${ }^{3}, K$ Komal Safdar ${ }^{3}$, Muhammad $^{2}$ \\ Ahsan Shafiq ${ }^{4}$ and Tehreem Fatima ${ }^{5}$ \\ ${ }^{1}$ House Surgeon, KRL Hospital Islamabad, Former House Physician, Holy Family Hospital Rawalpindi, Guys \& St Thomas \\ Hospital, NHS Foundation Trust UK
}

${ }^{2}$ Resident Paediatrics, Holy Family Hospital Rawalpindi

${ }^{3}$ House Physician, Dr Akbar Niazi Teaching Hospital Islamabad

${ }^{4}$ Resident Internal Medicine, Holy Family Hospital Rawalpindi, CIBNP, Fairfield USA

${ }^{5}$ House Surgeon, Holy Family Hospital Rawalpindi, CIBNP, Fairfield USA

*Corresponding author: Hassan Mumtaz, 1House Surgeon, KRL Hospital Islamabad, Former House Physician, Holy Family Hospital

Rawalpindi, Guys \& St Thomas Hospital, NHS Foundation Trust UK

\begin{tabular}{|c|c|}
\hline ARTICLE INFO & ABSTRACT \\
\hline Received: 幽 September 26, 2020 & Persistent hypokalemia is frequently seen in Distal Renal Tubular acidosis, which is \\
\hline Published: 梆 October 05, 2020 & $\begin{array}{l}\text { rarely described in children. We report a case of hypokalemic hyperchloremic metabolic } \\
\text { acidosis due to distal RTA who was also found to have renal medullary nephrocalcinosis } \\
\text { changes. This case report highlights the importance of considering hypokalemia and renal }\end{array}$ \\
\hline
\end{tabular}

Tubular Acidosis. Biomed J Sci \& Tech Res

30(5)-2020. BJSTR. MS.ID.005028.

\section{Introduction}

Distal renal tubular acidosis (RTA) is characterized by inability to secrete hydrogen irons from the distal tubule [1]. Clinical presentations in paediatric age group include polyuria, dehydration, failure to thrive, constipation, abnormal breathing and nephrolithiasis. Though persistent hypokalemia is frequently seen in dRTA, hypokalemic muscular paralysis is uncommon and rarely described in children [2]. Hypokalemic periodic paralysis is a rare disorder causing recurrent episodic weakness. Most cases are hereditary due to various channelopathies. Distal renal tubular acidosis (RTA) is an uncommon secondary cause of HPP, more so in children, with only few cases reported till date [3]. We report a case of hypokalemic hyperchloremic metabolic acidosis due to distal RTA who was also found to have renal medullary nephrocalcinosis changes.

\section{Case Presentation}

A 28day of life, female baby presented to the pediatric emergency weighing $2 \mathrm{~kg}$ with complain of failure to thrive and persistent dehydration despite adequate feed. She was born to G3P2 mother with no known antenatal risk factors and normal anomaly scan with birth weight of $3 \mathrm{~kg}$. She was a product of consanguineous marriage. History of death of 2 male siblings and she was only alive issue. She was currently taking formula milk with normal dilution. On examination she had severe dehydration and cachexia with marked temporal wasting, and no thrush was noticed. Her cardiopulmonary and abdominal evaluation was unremarkable. Genitalia were female type. Length was $50 \mathrm{~cm}$ and weight were $2 \mathrm{~kg}$ which were below 5 th centile for age Routine investigations were done showing in (Table 1). Renal function tests showed Urea of $18 \mathrm{mg} / \mathrm{dl}$ and creatinine of $0.7 \mathrm{mg} / \mathrm{dl}$. Serum electrolytes showed $\mathrm{K}+2.5, \mathrm{Na}+139, \mathrm{Cl}-115$. Venous blood gases showed metabolic acidosis (pH - 7.15, PCO2 - 35, HCO3-11.5meq/l) with a anion gap of 12.5 .

Urine examination showed ph of 6 wih sodium $122 \mathrm{mmol} / \mathrm{l}$, potassium $9.6 \mathrm{mmol} / \mathrm{l}$ and chloride of $87 \mathrm{mmol} / \mathrm{l}$ and was negative 
for reducing substances and protein glucose and aminoacids. Urinary Anion gap was positive .Renal ultrasound revealed bilateral. She had hyperchloremia (serum chloride-113meq/l). Urine calcium/creatinine ratio was high $(0.72 \mathrm{mmol} / \mathrm{mmol})$. Tubular resorption of phosphate was normal (> 80\%). The diagnosis of distal renal tubular acidosis was made, based on hypokalemic hyperchloremic metabolic acidosis with a normal anion gap, high urine $\mathrm{pH}$, hypercalciuria, medullary nephrocalcinosis and exclusion of other differential diagnosis. The child showed symptomatic recovery and upon commencement of standard treatment, which included thiazide diuretic for nephrocalcinosis and $\mathrm{k}$ and sodium bicarbonate supplements Patient is on regular follow up with monitoring of urine calcium-to-creatinine ratio, abgs serum electrolytes ultrasound kub and growth parameters. Dose of KCL and sodium bicarbonate was adjusted according to lab parameters. Growth parameters remained below 5th centile for age despite therapy.

Table 1.

\begin{tabular}{|c|c|}
\hline TLC & $\mathbf{1 8 . 3}$ \\
\hline HB & 15.7 \\
\hline PLT & 292 \\
\hline Neutrophils & 50 \\
\hline Lymphocytes & 40 \\
\hline Monocytes & 6 \\
\hline Eosinophils & 4 \\
\hline Calcium & 7.4 \\
\hline Ammonia & 85.6 \\
\hline Microscopic WBC & $2-3 /$ HPF \\
\hline Microscopic RBC & $200-250 /$ HPF \\
\hline Epithelial cells & Few / HPF \\
\hline Am. Urates & ++ \\
\hline
\end{tabular}

\section{Discussion}

Failure to thrive, constipation and persistent dehydration in patients can present with RTA. Nephrogenic diabetes insipidus can contribute to hypercalciuria which can be a cause of polyuria of RTA. Chronic constipation is also a cause of chronic hypokalemia which is associated with muscle weakness [4]. Results of thyroid function tests were normal in our case, whereas Congenital hypothyroidism shall be considered in differential diagnosis along with failure to thrive and constipation in infancy. In neonatal period the classical symptoms of hypothyroidism are typically seen in infancy. In our case the hyperchloremic metabolic acidosis with normal anion gap could be due to obstructive uropathy. To rule out hydronephrosis and hydroureters of obstructive uropathy ultrasound of the kidneys is an appropriate tool [5].

Calcium salts in the skeletal system become the next line of defense when extracellular bicarbonate and nonbicarbonate buffering systems are exhausted against the metabolic acidosis. The calcium released in exchange for the hydrogen ion obligates the kidney to increase calcium excretion to maintain calcium homeostasis. RTA is accompanied by hypercalciuria [4]. The hypocitraturia seen in this child, coupled with her high normal urine calcium excretion, increases the risk of nephrocalcinosis, which is characteristic of undiagnosed and untreated RTA. Indeed, if untreated or treated inadequately due to medical noncompliance, the nephrocalcinosis may worsen and ultimately destroy the kidneys, resulting in end-stage renal disease [6]. The nephrocalcinosis in RTA usually is unresolved, even with aggressive alkali therapy, in distinct contrast to diuretic-induced nephrocalcinosis in infancy, which resolves after cessation of the diuretic therapy.

\section{Conclusion}

Our case report highlights the importance of considering hypokalemia and renal tubular acidosis in the differential diagnosis. Early diagnosis can prevent costly investigations and rapid clinical recovery can be enabled in the affected child.

\section{References}

1. Albright F, Burnett CH (1946) Osteomalacia and late rickets. The various etiologies met in the United States with emphasis on that resulting from a specific form of renal acidosis, the therapeutic indications for each etiological sub-group, and the relationship between osteomalacia and Milkman's syndrome. Medicine 25(4): 399-479.

2. Bresolin NL, Grillo E, Fernandes VR (2005) A case report and review of hypokalemic paralysis secondary to renal tubular acidosis. Pediatr Nephrol 20(6): 818-820.

3. Ratan Gupta, Kumar Saurabh, Shobha Sharma (2013) Hypokalemic Periodic Paralysis and Distal Renal Tubular Acidosis Associated with Renal Morphological Changes. Indian Pediatrics 50: 336-337.

4. Cardas A, Broyer M, Dechaux M, Kleinknecht C (1992) Primary distal tubular acidosis in childhood: clinical study and long-term following of 28 patients. J Pediatr 121(2): 233-241.

5. James C, M Chan, Jon I (2001) Pediatrics in Review August 22(8): 277287.

6. Challa A, Chan W, Krieg RJ (1993) Effect of metabolic acidosis on the expression of insulin-like growth factor and growth hormone receptor. Kidney Int 44(6): 1224-1227. 


\section{ISSN: 2574-1241}

DOI: $10.26717 /$ BJSTR.2020.30.005028

Hassan Mumtaz. Biomed J Sci \& Tech Res

(C) (i) This work is licensed under Creative

Submission Link: https://biomedres.us/submit-manuscript.php

$\begin{array}{ll}\text { BIOMEDICAL } & \text { Assets of Publishing with us } \\ \text { RESEARCHES } & \text { Global archiving of articles } \\ \text { - Immediate, unrestricted online access }\end{array}$

